Article

\title{
Estimating the Contribution of New Seed Cultivars to Increases in Crop Yields: A Case Study for Corn
}

\author{
Jiarong Qian and Zhijun Zhao * \\ Institute of Agricultural Economics and Development, Chinese Academy of Agricultural Sciences, \\ Beijing 100081, China; qianjiarong@caas.cn \\ * Correspondence: zhaozhijun@caas.cn; Tel.: +86-10-8210-9786
}

Received: 30 June 2017; Accepted: 18 July 2017; Published: 22 July 2017

\begin{abstract}
Sustainability in agricultural development relies on continuing seed (cultivar) development and adoption. Measuring the contribution made by new seed cultivars to yield increases nationwide is essential, but this process remains challenging for academics. This study develops a method to estimate the overall contribution of new seed cultivars to crop yield increases by dividing the study period into several diffusion periods in terms of the replacement in major seed cultivars, and by defining a yield response model incorporating a series of dummy variables to capture net increases due to new cultivars' diffusion in each period. According to this method, corn cultivars tested in the period from 1980 to 2013 in China can be divided into five periods. Significant increases in corn yields due to cultivar replacement were captured, and the contributions over the base period were calculated as $61.7 \%, 47.6 \%, 46.0 \%$, and $48.9 \%$ for periods $2,3,4$, and 5 , respectively. Their respective contributions over the previous periods were therefore $61.7 \%, 34.6 \%, 26.7 \%$ and $56.7 \%$. Estimation results indicate that the introduction of new corn seed cultivars significantly contributed to corn yield increase. This method is likely to have practical applications for other crops or livestock.
\end{abstract}

Keywords: yield increase; seed cultivar; contribution; estimation; method

\section{Introduction}

Seed is the main input for crop production, and seed technology is therefore the most important aspect of agricultural technology in terms of the sustainable development of agriculture [1]. Past increases in crop yield have largely resulted from increases in input factors, but once these have been maximized, as under current agricultural practices, further large increases from agricultural inputs seem unlikely. Further improvement in input-use efficiency is still challenging to achieve via crop management practices [2], future crop yield gains are therefore likely to rely more heavily on the adoption of new and improved cultivars [3]. It is therefore important to be able to scientifically estimate the contribution of novel seed cultivars to crop yield increases in order to incorporate this information into agricultural and technological policy design. However, measuring new seeds' contribution to overall yield increase nationwide is not easy because of a lack of suitable variables to reflect the potential of the new seeds in terms of enhancing yield.

To investigate the contribution of such seeds in Chinese agriculture, most studies compared different cultivars in uniform regional nurseries [4-7]. However, because of the natural differences between nurseries and growers' conditions, the measurement of these contributions is irregular and uncertain, particularly when the figures generated are then used for nationwide or regional estimation of dissimilar conditions [8,9]. Several studies have also employed the Analytic Hierarchy Process (AHP) method to assess the contribution of seed in terms of agricultural technological change; this is an effective tool for dealing with complex assessments by reducing the complex factors to a series of pairwise comparisons and then synthesizing the results on the basis of the relative pairwise evaluations 
(both qualitative and quantitative) made by decision makers [10]. For example, He and He [11] used AHP to analyse the contributory share of each factor affecting agricultural technological change in Youzhong County, and the results suggested that seed accounted for the largest share of total technological progress at 25.6\%; Zhao and Zhang [1] employed AHP to evaluate the contribution for each specific factor affecting agricultural technological change in China, and they concluded that seed made the largest contribution among all technological aspects, with a share of $29.6 \%$ of the total contribution. However, although a general assessment of seed contribution can be made using the AHP method, AHP requires analysts to set weighted values for each factor, and those values depend on the subjective judgements of the analysts, who may therefore reach different conclusions. It is thus impossible for this method to generate objective results.

When examining seed contribution to yield gains, many studies have focused on exploring the contribution of genetic improvements [8,12-20]. For example, Feyerherm et al. [8] investigated the genetic contribution of seed cultivars to wheat yield increases by employing a differential yielding ability (DYA) value established by computing the mean difference in yields between the given cultivar and a primary check cultivar over a set of years and locations within a geographical region of mutual adaptability. Duvick [14] stated that an Iowa-adapted time-series of hybrids representing the period from 1930 to 2001 showed a linear gain for grain yield of $77 \mathrm{~kg} / \mathrm{ha}$ per year by employing a regression analysis based on trial data. A further examination of Duvick et al. [15] provided an estimate of $51 \%$ for the contribution of genetics, when trail yields are adjusted to the equivalent of average on-farm yields for Iowa during the period 1930 to 2001. Cargnin et al. [13] estimated the genetic progress of dryland wheat cultivars by computing the difference between the mean yield of a genotype one year and that of the previous year. Their results suggested that the mean estimated genetic progress for mean grain yield between 1976 and 2005 was $37 \mathrm{~kg} /$ ha per year. These studies have focused on quantifying the genetic contribution of seed-to-crop yield. However, yield increases nationwide are only partially dependent on genetic improvements in new seed cultivars: the correct diffusion of improved seed cultivars is also a very important aspect of enhancing crop yields. It is clear that one way to enhance yield level is to improve seed cultivars, while another way is to diffuse such improved cultivars over large areas. None of the studies examining genetic improvement referred to the contribution of seed diffusion to yield increase. Thus, the overall impact of seed cultivars in terms of both genetic improvement in seed cultivars and diffusion of improved cultivars on nationwide yield has not been well documented. In addition, most previous studies were conducted using methodologies adopted from natural sciences; few studies in this field have employed economic methods.

The objective of this study is to develop a method, from the perspective of agricultural economics to investigate the contribution of new seed cultivars to nationwide corn yield increases in China during 1980 and 2013. To facilitate this, the term contribution of new seed cultivars as used within this study will refer to both the contributions made by genetic improvement in new cultivars and the diffusion of the improved cultivars. The term new seed cultivars will refer to those seeds which have undergone genetic improvements and are adopted to replace current seed cultivars in general production in large areas. This study contributes findings of practical and heuristic significance in terms of measuring the developmental status of both seed breeding technologies and agriculture.

\section{Materials and Methods}

\subsection{Methodology}

Normally, new seeds are developed and diffused into agricultural production regularly, and their diffusion may last for a few years. These new seeds' yielding ability can therefore only be fully demonstrated during their entire diffusion period, and estimating the contribution of seeds throughout the entire diffusion period is more scientific and reasonable than studying only one instance. In order to assess the contribution of seed cultivars to yield increases, the study period can be divided into 
several diffusion periods, with regards to the replacement of the major cultivars and estimations made of the overall contribution in each diffusion period.

Figure 1 illustrates the evolution of diffusion for crop seed cultivars. If there is no obvious change in major seed cultivars from $t_{0}$ to $t_{1}$, then we can set period $t_{0}-t_{1}$ as period one (the base period). If new seed cultivars are extensively planted in period $t_{1}-t_{2}$, this period can be identified as period two. The remaining periods can be deduced by analogy until period $n$.

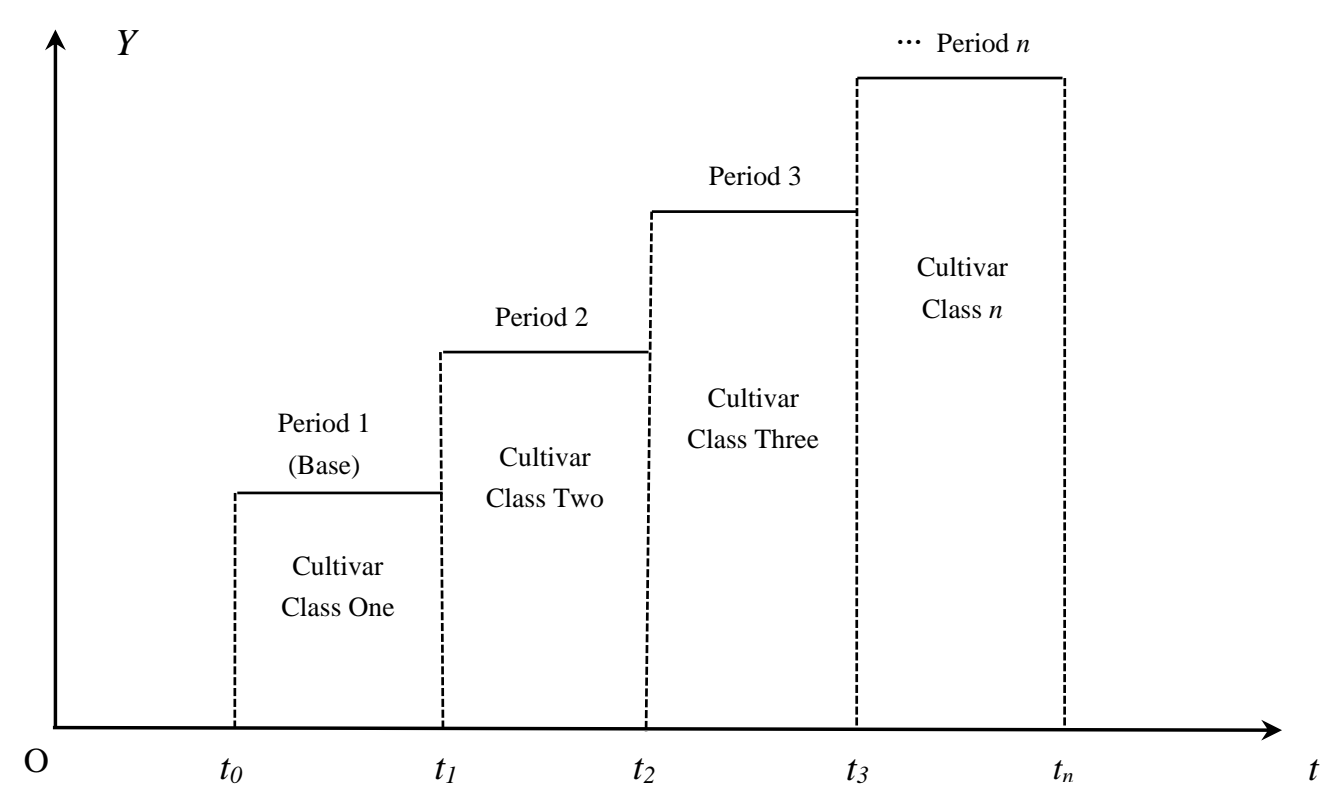

Figure 1. Seed diffusion periods in China, bordered on the time of change in adoption of new cultivars.

Figure 2 presents the yield curve for each period. Supposing the new diffused seed cultivars lead to significant increase in crop yield with an average increase of $h$. The yield curve will also move upward by $h$, in that the intercept will increase by $h$. Any decreases will also decrease the intercept. Here, $h$ represents the contributory proportion of new seed cultivars to crop yield increases, the key to measuring new seed cultivars' contribution is therefore to estimate the $h$.

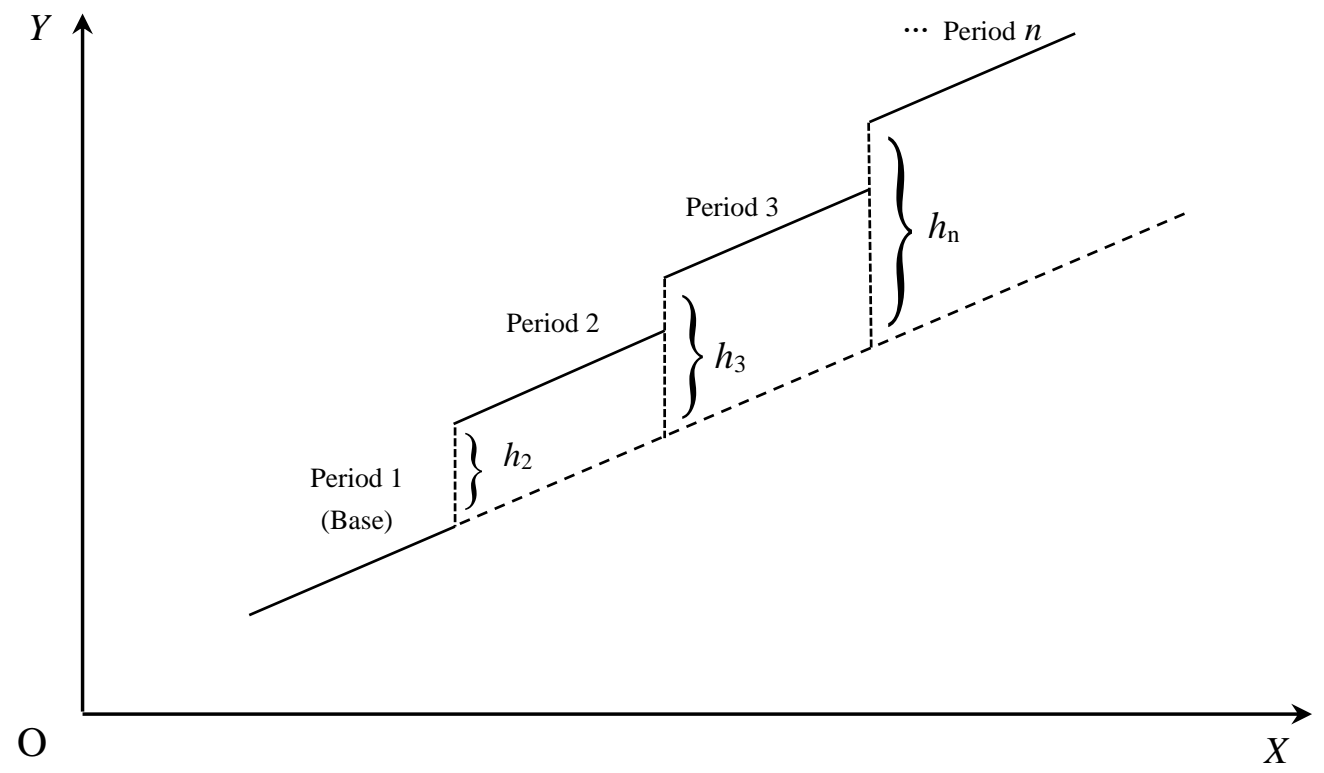

Figure 2. Yield curves in each diffusion period. 
Although previous studies have developed various yield models to predict crop yields [21-24], these have several limitations. Taking into account that (1) sufficient data for constructing a production function for yield is generally unavailable; (2) crop yield is significantly sensitive to crop producer prices (a producer price is the average price or unit value received by farmers at the farm gate) $[25,26]$; and (3) a supply response model that contains crop producer prices is therefore more powerful in explaining changes in supply variables (area, yield, and production), the crop yield model used in this study is specified as a yield response equation. The response equation is derived from the adaptive expectation theory. This theory links farmers' behaviors to their expected prices and posits that farmers react not to the previous year's price but rather to the price they anticipate in the current year, and that this expected price depends only to a limited extent on the previous year's price $[27,28]$. Formally, the adaptive expectation is written as

$$
P_{t}^{e}=P_{t-1}^{e}+\lambda\left(P_{t-1}-P_{t-1}^{e}\right)
$$

where $P_{t}^{e}$ is the expected price in year $t ; P_{t-1}^{e}$ represents the expected price in year $t-1 ; P_{t-1}$ represents the actual price in the previous year; and $\lambda$ is the coefficient of expectation with $0<\lambda \leq 1$, which reflects how much information producers retain in their current year's expectations from outcomes observed in the previous year. Farmers will revise their expected price in terms of the difference between the previous year's actual price and the expected price, rather than simply using the previous year's price as the current year's expected price [29].

The basic yield equation can be written as

$$
Y_{t}=\alpha_{0}+\alpha_{1} P_{t}^{e}+\mu_{t}
$$

where $Y$ represents crop yield; $P^{e}$ is the expected producer price for crop; $\mu$ is a random residual term, $t$ is the year; and $\alpha_{0}$ and $\alpha_{1}$ are coefficients to be estimated. Unfortunately, the expected price cannot be observed, and thus these coefficients cannot be estimated. To solve this problem, here we include Equation (3), the basic yield equation in the previous year.

$$
Y_{t-1}=\alpha_{0}+\alpha_{1} P_{t-1}^{e}+\mu_{t-1}
$$

Combining the adaptive expectation Equation (1) and the yield Equations (2) and (3) leads to a basic yield response model of

$$
Y_{t}=\alpha+\beta_{0} Y_{t-1}+\beta_{1} P_{t-1}+v_{t}
$$

where $\alpha$ turns out to be equal to $\alpha_{0} \lambda, \beta_{0}$ equals $1-\lambda, \beta_{1}$ equals $\alpha_{1} \lambda$, and $\mathrm{v}$ is a random residual that differs from $\mu$. Most importantly, all variables are observed, and therefore parameters can be estimated using observed data. This model is so called Nerlove model, which has been widely applied to estimate this dynamic process in crop production [25,30-33].

To capture the contribution of a different class of seed cultivars to increases in crop yields, a series of dummy variables representing various diffusion periods are incorporated into the basic yield response model in combination with the earlier analysis on division of various cultivar diffusion periods, and parameters on these dummy variables capture the net average increases over the base period attributed to the adoption of the improved cultivars in each diffusion period (the detailed proof process is shown in the Appendix A). The resulting extended yield response model is shown as

$$
Y_{t}=\alpha+\beta_{0} Y_{t-1}+\beta_{1} P_{t-1}+\beta \mathrm{D}+v_{t}
$$

where $\mathrm{D}$ indicates a series of dummy variables distinguishing diffusion periods for various seed cultivars. Here $\beta$ represents the net increase caused by new seed cultivar diffusion. If the adoption and diffusion of new seed cultivars significantly promotes crop yield, overall average yield during the 
diffusion period should rise, and $\beta$ the coefficient on dummy variables is expected to take a positive sign; otherwise, a negative sign is expected.

In the next section, we apply this method to estimate new corn cultivars' contribution to corn yield increases in China and check the estimated results.

\subsection{Model Specification for Corn in China}

This study applies the above method to estimate the contribution of seed cultivars-using corn in China as a case study. In terms of changes in major diffused corn cultivars during the period 1980 to 2013, the diffusion period for corn seeds can be divided into five segments: the first period was from 1980 to 1986, when Zhongdan No. 2 (ZD No. 2) was planted in extremely large areas; the second period was from 1987 to 1994, when Danyu No. 13 (DY No. 13) replaced ZD No. 2 as the most diffused cultivar; the third period ranged from 1995 to 1999, during which DY No. 13 was moved from first place and Yedan No. 13 (YD No. 13) began to be adopted and diffused in most corn regions in China; the fourth period was from 2000 to 2003, when the major cultivar was changed to Nongda No. 108 (ND No. 108); and finally, the fifth period was from 2004 to 2013, when the top corn seed cultivar was Zhengdan No. 958 (ZD No. 958) (See Figure 3).

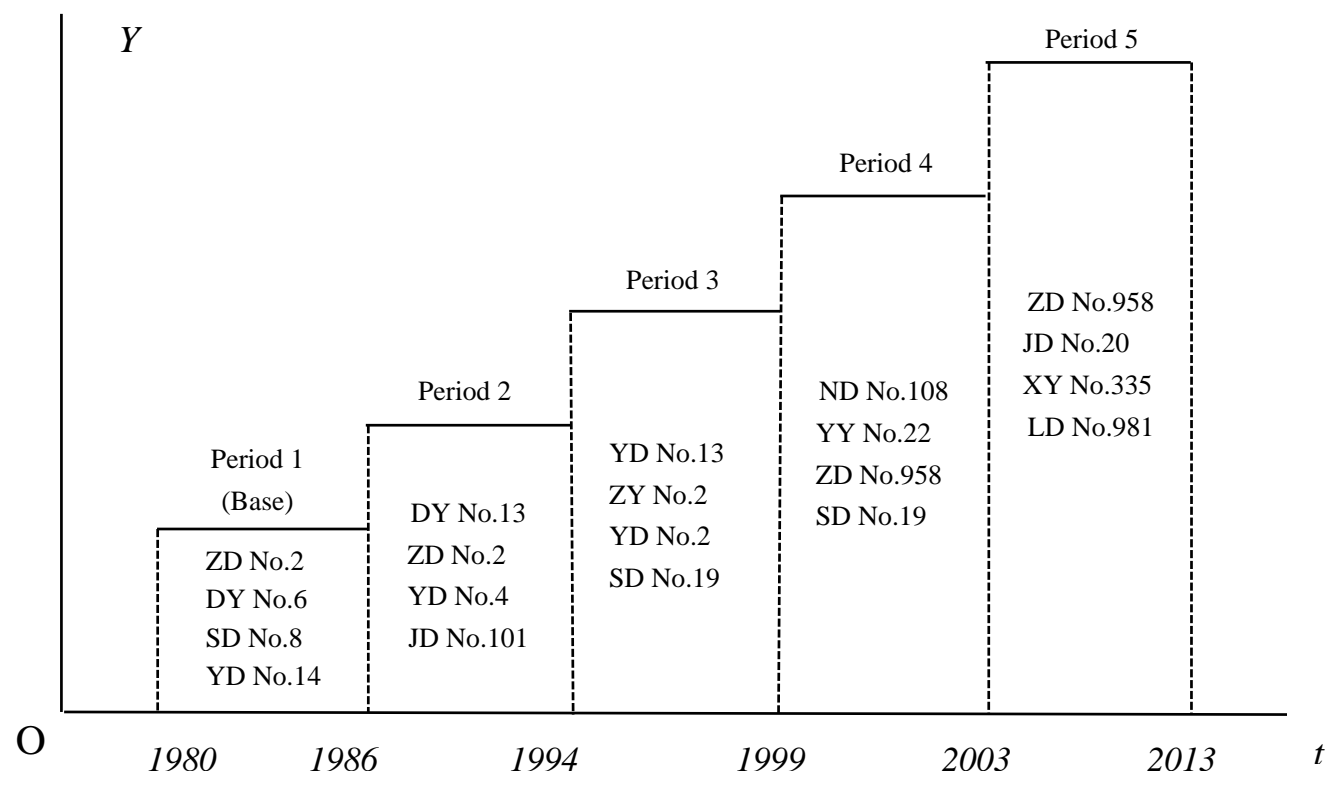

Figure 3. Distribution of major diffused cultivars for corn in China 1980 to 2013.

Due to the diffusion period for corn seed cultivars' division into five distinct periods between 1980 and 2013, corn yield can be specified as a model by including four dummy variables into the basic yield response equation:

$$
Y_{i t}=C+\beta_{0} Y_{i t-1}+\beta_{1} P_{i t-1}+\beta_{2} \mathrm{D} 2+\beta_{3} \mathrm{D} 3+\beta_{4} \mathrm{D} 4+\beta_{5} \mathrm{D} 5
$$

where $Y$ indicates corn yield; $P$ represents corn producer prices; $i$ indicates the main producing provinces in China; $t$ is the year from 1980 to 2013 and $t-1$ represents the previous year, lagged; and D2-D5 are dummy variables distinguishing different diffusion periods. D2 denotes seed diffusion period two, with 1987 to 1994 as 1, otherwise, 0; D3 represents diffusion period three, with 1995 to 1999 as 1, otherwise, 0; D4 represents diffusion period four, with 2000 to 2003 as 1, otherwise, 0; and D5 represents diffusion period five, with 2004 to 2013 as 1, otherwise, 0. 


\subsection{Data Sources}

Provincial panel data from 1980 to 2013 in China are used for estimation. Data on corn yields are obtained from the China Rural Statistical Yearbook. Price data are drawn from the National Cost and Return of Agricultural Products in China and are expressed in real terms with 1980 as the base year. Information on major cultivars diffused in each province is from the annual internal reports (from 1980 to 2014) provided by the Seed Administration of the Ministry of Agriculture of China.

\section{Results}

\subsection{Estimated Results}

The yield equation is a dynamic panel model, and when estimating dynamic panel models, the Ordinary Least Square (OLS) method does not work due to existence of endogeneity; thus, the Arellano-Bond dynamic panel generalized method of moments (GMM) is used to estimate the coefficients. This estimation method can correct the regression bias caused by endogeneity [34]. The estimated results are reported in Table 1.

Table 1. Estimated results for corn yield equation using Arellano-Bond generalized method of moments (GMM).

\begin{tabular}{ccccc}
\hline Coefficients & Estimate & Std. Error & $\boldsymbol{t}$-Value & Prob. \\
\hline $\mathrm{C}$ & 1796.95 & 309.75 & 3.92 & 0.000 \\
$\mathrm{Y}_{\mathrm{t}-1}$ & 0.36 & 0.09 & 2.39 & 0.000 \\
$\mathrm{P}_{\mathrm{t}-1}$ & 18.27 & 7.66 & 5.90 & 0.017 \\
$\mathrm{D} 2$ & 487.27 & 82.57 & 5.01 & 0.000 \\
$\mathrm{D} 3$ & 782.36 & 156.08 & 6.94 & 0.000 \\
$\mathrm{D} 4$ & 819.25 & 118.11 & 5.62 & 0.000 \\
$\mathrm{D} 5$ & 1192.09 & 212.07 & 5.80 & 0.000 \\
Method = A-Bond GMM & \multicolumn{4}{c}{ Obs. $=988$} \\
\hline
\end{tabular}

The estimated results show that all estimates on dummy variables are highly significant at the $0.1 \%$ significance level and take positive signs, strongly suggesting that the model adequately captures the net increases in corn yield due to the diffusion of different seed cultivars. The parameters on the dummy variables represent the average increases in corn yields attributed to new seed diffusion over the average yield in the base period. For instance, the parameter for D2 is 487.27 , which implies that new seed diffusion in period two (1987 to 1994) increased the average yield by $487.27 \mathrm{~kg} / \mathrm{ha}$ over the average in the base period (1980 to 1986). Likewise, in period three (1995 to 1999), the average increase was $782.36 \mathrm{~kg} / \mathrm{ha}$, a net increase of $295.09 \mathrm{~kg} / \mathrm{ha}$ or $60.6 \%$ over the increase in period two, indicating that corn yields in this period were promoted by $782.36 \mathrm{~kg} /$ ha relative to the base period. In period four (2000 to 2003), the rise was $819.25 \mathrm{~kg} / \mathrm{ha}$, an increase of $36.89 \mathrm{~kg} / \mathrm{ha}$ or $4.7 \%$ over that in the previous period. Finally, in period five (2004 to 2013), the increase due to new seed diffusion jumped to a high of $1192.09 \mathrm{~kg} / \mathrm{ha}$, an increase of $372.84 \mathrm{~kg} / \mathrm{ha}$ or $45.5 \%$ over that in period four. Overall, the average increase in corn yields due to diffusion of new cultivars over the base period rose dramatically over time, indicating a significant improvement in seed breeding and diffusion.

\subsection{Contribution Calculation}

Table 2 reports the detailed changes in corn yield and contribution of new cultivars. The yield average in the base period (1980-1986) was $2852.4 \mathrm{~kg} / \mathrm{ha}$, and this increased to $3642.5 \mathrm{~kg} / \mathrm{ha}$ in period two (1987-1994), an improvement of $790.1 \mathrm{~kg} / \mathrm{ha}$; of this, new cultivars contributed $487.3 \mathrm{~kg} / \mathrm{ha}$ to the total increase, so the contribution of the new seed cultivars equaled $61.7 \%$ in this diffusion period. In period three, the average yield of corn grew to $4494.9 \mathrm{~kg} / \mathrm{ha}$, an increase of $1642.5 \mathrm{~kg} / \mathrm{ha}$ over the average in the base period, of which $782.4 \mathrm{~kg} / \mathrm{ha}$ was attributed to new seed cultivars. Thus, the 
contribution of new seeds for the third diffusion period was $47.6 \%$. In period four, corn average yield was $4633.2 \mathrm{~kg} / \mathrm{ha}, 1780.8 \mathrm{~kg}$ higher than the base period, and new seed diffusion was estimated as being responsible for $819.3 \mathrm{~kg} / \mathrm{ha}$ of the total increase, resulting in a contribution rate of $46.0 \%$ for this period. This was the only period in which a decrease was seen in the proportion of improvement attributed to new seed diffusion, with the contribution being estimated as $1.6 \%$ lower than the previous period. This was caused by a larger increase attributed to other factors, which overshadowed the contribution share from seed cultivars and led to a decrease in relative seed contribution in this period. There was then a significant increase in the contribution of new seed cultivars in the fifth diffusion period, with the increase due to new seed diffusion jumping from $819.3 \mathrm{~kg} / \mathrm{ha}$ to $1192.1 \mathrm{~kg} / \mathrm{ha}$, a net increase of $372.8 \mathrm{~kg} / \mathrm{ha}$ or $45.5 \%$. The total increase in corn yield average was increased to $5290.9 \mathrm{~kg} / \mathrm{ha}$, a jump of $2438.5 \mathrm{~kg} /$ ha from the base period, so the contribution rate increased to $48.9 \%, 2.9 \%$ higher than that in the fourth period. These estimated results suggest that new seed cultivars significantly contribute to rises in corn yields, and that development in seed technologies and seed diffusion succeeded in making significant progress in China over the past two decades under consideration.

Table 2. Contribution of new cultivars to corn yield increases in each diffusion period ( $\mathrm{kg} / \mathrm{ha}, \%)$.

\begin{tabular}{|c|c|c|c|c|c|c|c|}
\hline $\begin{array}{c}\text { Diffusion } \\
\text { Period }\end{array}$ & $\begin{array}{c}\text { Average } \\
\text { Yield }\end{array}$ & \multicolumn{3}{|c|}{ Over the Base Period } & \multicolumn{3}{|c|}{ Over the Previous Period } \\
\hline $2(87-94)$ & 3642.5 & 790.1 & 487.3 & 61.7 & 790.1 & 487.3 & 61.7 \\
\hline $3(95-99)$ & 4494.9 & 1642.5 & 782.4 & 47.6 & 852.4 & 295.1 & 34.6 \\
\hline
\end{tabular}

The seed contribution over the previous period for period two is therefore the same as that over the base period, $61.7 \%$, because the comparison is made between the same two periods. In period three, the average corn yield was $4494.9 \mathrm{~kg} / \mathrm{ha}, 852.4 \mathrm{~kg} / \mathrm{ha}$ higher than the previous period, and the increase caused by seed replacement over period two was estimated as $295.1 \mathrm{~kg} / \mathrm{ha}$. Thus, the contribution of new seed cultivars in period three over the previous period was $34.6 \%$. In the fourth period, corn average yield only exhibited a slight increase, from $4494.9 \mathrm{~kg} / \mathrm{ha}$ in the previous period to $4633.2 \mathrm{~kg} / \mathrm{ha}$, a net increase of only $138.3 \mathrm{~kg} / \mathrm{ha}$, and the increase due to new seed diffusion shrank to $36.9 \mathrm{~kg} / \mathrm{ha}$, causing the seed contribution rate to drop to $26.7 \%, 7.9$ percentage points less than that in the previous period. Finally, in the fifth diffusion period, a significant increase was witnessed in seed contribution. The increase due to new seed diffusion jumped from the previous $819.3 \mathrm{~kg} / \mathrm{ha}$ to $1192.1 \mathrm{~kg} / \mathrm{ha}$, a rise of $372.8 \mathrm{~kg} / \mathrm{ha}$ or $45.5 \%$. Meanwhile, the corn yield average in this period was $5290.9 \mathrm{~kg} / \mathrm{ha}$, an increase of $657.6 \mathrm{~kg} / \mathrm{ha}$ or $14.2 \%$ over the average in period four. As a result, seed contribution in this period reached a high of $56.7 \%, 30$ percentage points more than that during the fourth diffusion period, indicating that newly diffused cultivars promoted corn yield significantly and that their contributory share exceeded the sum of all other factors driving corn yield (See Table 2).

\section{Discussion}

Yield gains nationwide do depend on genetic improvement in cultivars, but they are also affected by the diffusion of those improved cultivars. These connected factors mean that only the overall contribution of cultivars, including both genetic improvement and diffusion, can be used to reflect the progress in seed development and spread in a country. While most previous studies used cultivars' performance trial data to investigate the contribution of genetic improvement in cultivars, this creates problems in terms of extrapolating from nurseries to actual growing conditions. Thus, results based on such trials are likely to overestimate the yield improvement on farms from the use of the new cultivars [35]. The actual impact of such tested cultivars, taking into account the effects of weather, 
disease, and varying production conditions in large areas, remains highly uncertain. Nevertheless, its estimation is very important for planning purposes, and finding better ways to measure the overall actual contribution makes significant sense in terms of governmental and political decision making.

In a departure from most previous studies, this study developed a method aiming to estimate the overall contribution, rather than only the genetic contribution, to yield gains that can be attributed to new seeds from improvements in both breeding and diffusion as estimated by capturing changes in the intercept of the yield curve. Other factors such as weather variability, disease, input usage, and field management also affect crop yields, and controlling for these factors is problematic for those studies using trial data [18]. In this instance, these are comprehensively represented by a technical process employing a proxy variable of lagged yield [36,37]. Further, farm field yield data is used for estimation, and thus the estimated contribution represents the actual impact of new cultivars. Using this method, the overall contribution of new corn seed cultivars has been estimated. According to the estimated results, the coefficients representing intercept movement are all positive, meaning that yield curve shifts upward and new corn cultivars in each period continuously improved corn yields in China. Theoretically, the coefficient could be negative, if the estimated value took a negative sign, which would indicate that the yield curve was reducing, and that new seed cultivars were failing to enhance crop yields. In such a case, the government should make efforts to develop new cultivars with higher yield ability or to try to expand the diffusion areas of the new cultivars so as to improve the seed cultivars' contribution. The estimation in our study was based on a relatively large sample size of provincial panel data, which improved the precision and stability of the coefficients, and thus the reliability of the results. Increases in corn yield due to new cultivars had been captured in each diffusion period. These results indicate that improved corn seeds significantly enhanced corn yields in China during the period under investigation. In particular, the contribution of new cultivars in the final diffusion period was over $50 \%$ (over the previous period), exceeding the total contributory share of other factors and indicating that seed became the essential factor driving corn yield increases in China at that point. This finding is in line with the qualitative results of previous studies using AHP, which concluded that seed made the largest contribution among all factors affecting crop yield [1,11]. As stated earlier, AHP depends on pairwise relative evaluations made by decision makers (analysts), and cannot, therefore, lead to an objective result. Nevertheless, it remains an effective tool for determining the most important factor by means of ranking all known influence factors. The current results were supported by the results from AHP, providing corroboration for both types of investigation. The suggested method involves only few variables, making it uncomplicated, and the data involved can be easily collected from yearbooks or official reports. Based on these facts, this method can be easily utilized in practical applications. In addition, the contribution indicator thus generated can be reported annually by updating the annual data, satisfying the governmental demand for annual assessment of the progress of the breeding program and the work of new cultivar diffusion. Corresponding policies for agricultural development, particularly for the seed sector, could therefore be designed with reference to these tracking assessments.

This method only estimates the comprehensive contribution of seed cultivars in a given period, but this should be sufficient for the government to make an overall judgment on the status of seed development and diffusion. In the future, additional studies may aim to investigate the contribution of specific cultivars and to separate the effects of diffusion from the overall contribution.

\section{Conclusions}

Assessing the contribution of new seed cultivars to nationwide yield increases is a challenging but essential task. This study developed a method to estimate the contribution of new seed cultivars to yield increases by constructing a yield response model in which a series of dummy variables were included to capture the contributions of various cultivar classes during their diffusion periods, defined by the replacement of major cultivars. Within this method, the parameters for the dummy variables represent the net increase attributed to new seed cultivars over the base period. The estimated results 
indicate that corn seeds significantly enhanced corn yields in China during the past three decades; in particular, the contribution of corn seed in the most current diffusion period was more than $50 \%$ over the previous period, indicating that seed cultivars have become an essential factor driving corn yield to increase in China.

This study has presented a method enabling the overall contribution of seed cultivars to yield increase to be approximated. This method has several advantages, being concise, easy to use, and flexible. Furthermore, it can distinguish historical contributions of seed and can therefore be used for tracking assessments. It is therefore likely to be a good method applied to actual measurement of progress in seed breeding technologies and agricultural development.

Acknowledgments: This research is financially supported by the Agricultural Science and Technology Innovation Program (ASTIP-IAED-2016-05), the Project Sponsored by the Ministry of Agriculture of the People's Republic of China (11162130109236061), and the Project Sponsored by the Basic Research Foundation for the Central Public Institutes (0052015001-1). The authors would like to thank the anonymous reviewers for their constructive comments and suggestions on improving this paper.

Author Contributions: Jiarong Qian designed the method and conducted the research; Zhijun Zhao was involved in result discussion and revision of this paper. All authors have read and approved the final draft.

Conflicts of Interest: The authors declare no conflict of interest.

\section{Appendix A}

Here we provide the mathematical proof process of estimating seed contribution to yield increase. To simplify the equation, we define the crop yield equation as:

$$
Y=C+\alpha X+\beta D
$$

where $Y$ indicates crop yield; $X$ represents the main variables influencing crop yield; $D$ represents a dummy variable reflecting changes in seed diffusion; and $C$ is the intercept. Suppose the first diffusion stage, $t$, is from 0 to $k$, and the $n$th stage when the major diffused seed cultivars are changed is from $i$ to $n$. The individual yield equations for each year in both periods are therefore as follows:

$$
\begin{array}{lc}
Y_{0}=C+\alpha X_{0} & Y_{i}=C+\alpha X_{i}+\beta \\
Y_{1}=C+\alpha X_{1} & Y_{i+1}=C+\alpha X_{i+1}+\beta \\
Y_{2}=C+\alpha X_{2}, \text { and } & Y_{i+2}=C+\alpha X_{i+2}+\beta \\
\vdots & Y_{i+n}=C+\alpha X_{i+n}+\beta
\end{array}
$$

By adding these two groups of equations, we obtain

$$
\begin{gathered}
\sum_{t=0}^{k} Y_{t}=k C+\alpha \sum_{t=0}^{k} X_{t} \\
\sum_{t=i+1}^{i+n} Y_{t}=n C+\alpha \sum_{t=i+1}^{i+n} X_{t}+n \beta
\end{gathered}
$$

then, the average yield functions for 1 and $n$ periods are obtained by dividing by $k$ and $n$ for both sides of Equations (A3) and (A4), respectively. These are expressed as follows:

$$
\begin{gathered}
\frac{1}{k} \sum_{t=0}^{k} Y_{t}=C+\frac{\alpha}{k} \sum_{t=0}^{k} X_{t} \\
\frac{1}{n} \sum_{t=i+1}^{i+n} Y_{t}=C+\frac{\alpha}{n} \sum_{t=i+1}^{i+n} X_{t}+\beta
\end{gathered}
$$


Subtracting Equation (A5) from Equation (A6), the increase in average yield in period $n$ over period 1 is expressed as

$$
\Delta Y=\frac{1}{n} \sum_{t=i+1}^{i+n} Y_{t}-\frac{1}{k} \sum_{t=0}^{k} Y_{t}=\alpha\left(\frac{1}{n} \sum_{t=i+1}^{i+n} X_{t}-\frac{1}{k} \sum_{t=0}^{t=k} X_{t}\right)+\beta
$$

where $\Delta Y$ indicates the increase in average yield from period $n$ to period $1 ; k, n, Y$, and $X$ are observed variables; $\alpha$ and $\beta$ are parameters that can be estimated, and $\beta$ is the increase caused by new seed cultivars. Finally, the contribution rate of new seed cultivars can be calculated by

$$
C R=\frac{\beta}{\Delta Y} \times 100 \%
$$

In addition, this method can be extended to make a comparison between any two diffusion periods; the contribution formula is

$$
C R=\frac{\Delta \beta}{\Delta Y} \times 100 \%
$$

The mathematical proof process for this formula (A9) is similar to that demonstrated for the previous formula (A8).

\section{References}

1. Zhao, Z.J.; Zhang, S.M. A quantitative analysis on factors driving agricultural technical progress. Issues Agric. Econ. 2005, s1, 70-75.

2. Martin, K.L.; Hodgen, P.J.; Freeman, K.W.; Melchiori, R.; Arnall, D.B.; Teal, R.K.; Mullen, R.W.; Desta, K.; Phillips, S.B.; Solie, J.B.; et al. Plant-to-plant Variability in Corn Production. Agron. J. 2005, 97, 1603-1611. [CrossRef]

3. Tokatlidis, I.S. Adaptation to density to optimize grain yield: Breeding implications. Euphytica 2017, 213, 92. [CrossRef]

4. Wang, W.; Liao, Z. Experiment comparison for new late rice cultivars in Ningdu County in 2014. Seed World 2015, 8, 16-19.

5. Liu, H.; Zhu, Y.; Feng, W. Study on the characteristics of the new maize cultivar Xinzhongyu 801 and its potentiality to increase maize yield. Seed 2015, 34, 111-114.

6. Shi, Z.; Yang, Y.; Li, F.; Wang, Z.; Wang, H.; Lv, X. Study on yield increasing potential of Danyu 39. Seed 2010, $29,72-74$.

7. Tian, H.; Guo, S.; Chen, L.; Zhou, T. The contribution of new cultivars to increasing rapeseed yield. Seed 2006, 25, 73-76.

8. Feyerherm, A.M.; Paulsen, G.M.; Sebaugh, J.L. Contribution of genetic improvement to recent wheat yield increases in the USA. Agron. J. 1984, 76, 985-990. [CrossRef]

9. Dalrymple, D.G. Development and Spread of Semidwarf Varieties of Wheat and Rice in the United States: An International Perspective; USDA Agricultural Economic Report No.455; U.S. Department of Agriculture, Economics, Statistics, and Cooperatives Service: Washington, DC, USA, 1980.

10. Saaty, T.L. The Analytic Hierarchy Process; McGraw-Hill: New York, NY, USA, 1980.

11. He, M.X.; He, C.F. Measuring technical change in agriculture: The Analytical Hierarchy Process method. J. Inn. Mong. Normal Univ. 1995, 2, 6-11.

12. Tian, Z.; Jing, Q.; Dai, T.; Jiang, D.; Cao, W. Effects of genetic improvements on grain yield and agronomic traits of winter wheat in the Yangtze River Basin of China. Field Crops Res. 2011, 124, 417-425. [CrossRef]

13. Cargnin, A.; Souza, M.A.D.; Fronza, V.; Fogaca, C.M. Genetic and environmental contributions to increased wheat yield in Minas Gerais, Brazil. Sci. Agric. 2009, 3, 317-322. [CrossRef]

14. Duvick, D.N. Genetic progress in yield of United States maize (Zea mays L.). Maydica 2005, 50, 193-202.

15. Duvick, D.N. The contribution of breeding to yield advances in maize (Zea mays L.). Adv. Agron. 2005, 86, 83-145. 
16. Ma, Z.Y.; Wu, Y.C. Contribution of rice genetic improvement to yield increase in China. Chin. J. Rice Sci. 2000, 14, 112-114.

17. Wu, Y.C.; Ma, Z.Y.; Wang, D.Y.; Jiang, J. Contribution of maize improvement to yield increment in China. Acta Agron. Sin. 1998, 24, 595-599.

18. Bell, M.A.; Fischer, R.A.; Byerlee, D.; Sayre, K. Genetic and agronomic contributions to yield gains: A case study for wheat. Field Crops Res. 1995, 44, 55-65. [CrossRef]

19. Russell, W.A. Genetic improvement of maize yields. Adv. Agron. 1991, 46, 245-298.

20. Feyerherm, A.M.; Kemp, K.E.; Paulsen, G.M. Genetic contribution to increased wheat yields in the USA between 1979 and 1984. Agron. J. 1989, 81, 242-245. [CrossRef]

21. Feyerherm, A.M.; Paulsen, G.M. Development of a wheat yield prediction model. Agron. J. 1981, 73, $277-282$. [CrossRef]

22. Bell, M.A.; Fischer, R.A. Using yield prediction models to assess yield gains: A case study for wheat. Field Crops Res. 1994, 36, 161-166. [CrossRef]

23. Zere, T.B.; Van Huyssteen, C.W.; Hensley, M. Development of a simple empirical model for predicting maize yields in a semi-arid area. S. Afr. J. Plant Soil 2005, 22, 22-27. [CrossRef]

24. Mirschel, W.; Wieland, R.; Wenkel, K.O.; Nendel, C.; Guddat, C. YIELDSTAT—A spatial yield model for agricultural crops. Eur. J. Agron. 2014, 52, 33-46. [CrossRef]

25. Qian, J.; Ito, S.; Isoda, H.; Saito, H. Yield Response to Price and High-quality Seed Subsidy Policies in China. Jpn. J. Farm Manag. 2012, 50, 118-123.

26. Qian, J.; Ito, S.; Mu, Y.; Zhao, Z. Simulations on the Impact of Subsidy Policies on Grain Supply and Demand in China; China Agriculture Press: Beijing, China, 2015.

27. Nerlove, M. Estimates of the elasticities of supply of selected agricultural commodities. J. Farm Econ. 1956, 38, 496-509. [CrossRef]

28. Nerlove, M.; Bachman, K.L. The analysis of changes in agricultural supply: Problems and approaches. J. Farm Econ. 1960, 42, 531-554. [CrossRef]

29. Jeffrey, D.; Hamady, D.; Aminata, S. Estimating the supply response of cotton and cereal crops in smallholder production systems: Recent evidence from Mali. Agric. Econ. 2009, 40, 519-533.

30. French, B.C.; Mathews, J.L. A supply response model for perennial crops. Am. J. Agric. Econ. 1971, 53, 478-490. [CrossRef]

31. Gafar, J. The supply response for sugar cane in Trinidad and Tobago: Some preliminary results. Appl. Econ. 1987, 19, 1221-1231. [CrossRef]

32. Froster, K.A.; Mwananmo, A. Estimation of dynamic maize supply response in Zambia. Agric. Econ. 1995, 12, 99-107. [CrossRef]

33. Mushtaq, K.; Dawson, P.J. Acreage response in Pakistan: A co-integration approach. Agric. Econ. 2002, 27, 111-121. [CrossRef]

34. Arellano, M.; Bond, S. Some tests of specification for panel data: Monte Carlo evidence and application to employment equations. Rev. Econ. Stud. 1991, 58, 277-297. [CrossRef]

35. Brennan, J.P. Measuring the contribution of new varieties to increasing wheat yields. Rev. Mark. Agric. Econ. 1984, 52, 1975-1995.

36. Wooldridge, J.M. Introductory Econometrics: A Modern Approach, 5th ed.; South Western: Cincinnati, $\mathrm{OH}$, USA, 2013.

37. Wang, D.; Zhang, Z.; Bai, C. Size of Government, rule of law, and the development of services sector. Econ. Res. J. 2007, 6, 51-64.

(C) 2017 by the authors. Licensee MDPI, Basel, Switzerland. This article is an open access article distributed under the terms and conditions of the Creative Commons Attribution (CC BY) license (http://creativecommons.org/licenses/by/4.0/). 